\title{
BMJ Open Obstructive sleep apnoea and the risk for coronary heart disease and type 2 diabetes: a longitudinal population- based study in Finland
}

\author{
Satu Strausz, ${ }^{1,2,3}$ Aki S. Havulinna, ${ }^{3,4}$ Tiinamaija Tuomi, ${ }^{3,5,6}$ Adel Bachour, ${ }^{7}$ \\ Leif Groop, ${ }^{3,8}$ Antti Mäkitie, ${ }^{9}$ Seppo Koskinen, ${ }^{4}$ Veikko Salomaa, ${ }^{4}$ \\ Aarno Palotie, ${ }^{3,10,11,12,13}$ Samuli Ripatti, ${ }^{3,14}$ Tuula Palotie ${ }^{1,2}$
}

To cite: Strausz $\mathrm{S}$,

Havulinna AS., Tuomi T, et al. Obstructive sleep apnoea and the risk for coronary heart disease and type 2 diabetes: a longitudinal population-based study in Finland. BMJ Open 2018;8:e022752. doi:10.1136/ bmjopen-2018-022752

- Prepublication history and additional material for this paper are available online. To view these files, please visit the journal online (http://dx.doi. org/10.1136/bmjopen-2018022752)

SR and TP contributed equally.

Received 4 March 2018

Revised 5 June 2018

Accepted 15 August 2018
Check for updates

(C) Author(s) (or their employer(s)) 2018. Re-use permitted under CC BY-NC. No commercial re-use. See rights and permissions. Published by BMJ.

For numbered affiliations see end of article.

Correspondence to

Satu Strausz;

satu.strausz@helsinki.fi

\section{ABSTRACT}

Objective To evaluate if obstructive sleep apnoea (OSA) modifies the risk of coronary heart disease, type 2 diabetes (T2D) and diabetic complications in a genderspecific fashion.

Design and setting A longitudinal population-based study with up to 25-year follow-up data on 36963 individuals (>500 000 person years) from three population-based cohorts: the FINRISK study, the Health 2000 Cohort Study and the Botnia Study.

Main outcome measures Incident coronary heart disease, diabetic kidney disease, T2D and all-cause mortality from the Finnish National Hospital Discharge Register and the Finnish National Causes-of-Death Register.

Results After adjustments for age, sex, region, highdensity lipoprotein (HDL) and total cholesterol, current cigarette smoking, body mass index, hypertension, T2D baseline and family history of stroke or myocardial infarction, OSA increased the risk for coronary heart disease ( $\mathrm{HR}=1.36, \mathrm{p}=0.0014,95 \% \mathrm{Cl} 1.12$ to 1.64$)$, particularly in women $(\mathrm{HR}=2.01,95 \% \mathrm{Cl} 1.31$ to 3.07 , $\mathrm{p}=0.0012$ ). T2D clustered with OSA independently of obesity ( $\mathrm{HR}=1.48,95 \% \mathrm{Cl} 1.26$ to $1.73, \mathrm{p}=9.11 \times 10^{-7}$ ). The risk of diabetic kidney disease increased 1.75-fold in patients with OSA ( $95 \% \mathrm{Cl} 1.13$ to $2.71, \mathrm{p}=0.013)$. OSA increased the risk for coronary heart disease similarly among patients with $\mathrm{T} 2 \mathrm{D}$ and in general population $(\mathrm{HR}=1.36)$. All-cause mortality was increased by $0 \mathrm{SA}$ in diabetic individuals $(\mathrm{HR}=1.35,95 \% \mathrm{Cl} 1.06$ to 1.71 , $\mathrm{p}=0.016$ ).

Conclusion OSA is an independent risk factor for coronary heart disease, T2D and diabetic kidney disease. This effect is more pronounced even in women, who until now have received less attention in diagnosis and treatment of OSA than men.

\section{INTRODUCTION}

Obstructive sleep apnoea (OSA) is a more common disorder than currently diagnosed in the clinic. ${ }^{1}$ It is a serious public health problem due to its many comorbidities, including an increased risk to coronary
Strengths and limitations of this study

- A large-scale population-based study of 36963 individuals with up to 25 years of follow-up.

- Follow-up registers have excellent validity and coverage.

- Our study takes a large amount of confounding factors related to obstructive sleep apnoea into consideration.

- Prospective study design should limit the risk of bias.

- Registry-based ascertainment through hospitalisation may miss non-hospitalised cases and treatment information.

heart disease (CHD) and type 2 diabetes (T2D)..$^{23}$ The main known risk factors for OSA are obesity, male gender, high age, increased neck circumference and problems of upper airway or jaw anatomy. ${ }^{4-7}$

Longitudinal studies have shown an association of OSA with incident or recurrent cardiovascular events and increased mortality. ${ }^{38}$ The risk of developing CHD is particularly increased in middle-aged men with OSA. ${ }^{9} 10$ Risk of CHD and mortality is usually increased if T2D is diagnosed before OSA. $^{11}$

There is mounting evidence that OSA is an independent risk factor for the development of T2D. ${ }^{212}{ }^{13}$ Most of the available studies have been cross sectional, ${ }^{6} 1213$ and not able to account for residual confounding factors. ${ }^{6}{ }^{13}$ Other studies did not distinguish between type 1 diabetes (T1D) and T2D, ${ }^{14}$ nor to generalise the results to the overall population. ${ }^{6}$ In some studies, this association has been dispersed after adjustments for other risk factors. ${ }^{15}$

Also, studies investigating the synergistic effects of OSA and T2D on the progression of 
diabetic kidney disease are scarce and often limited by a cross-sectional design ${ }^{16-18}$ or small sample size. ${ }^{19}$

To explore the role of OSA for CHD, T2D and increased mortality, we conducted a large-scale population-based study of 36963 individuals with up to 25 years of follow-up. We specifically aimed at evaluating (1) if OSA modifies the risk of CHD and T2D independently of known risk factors like body mass index (BMI), blood pressure and lipids, (2) the role of OSA for the development of diabetic complications including diabetic kidney disease and (3) examine if OSA has similar effects in women and men.

\section{METHODS}

\section{Study population}

We included 36963 participants in our study from national FINRISK Studies (FINRISK), Health 2000 Cohort (H2000) and a subset of the Botnia and Prevalence, Prediction and Prevention of Diabetes (PPP)Botnia Studies (Botnia) including 1568 (4.2\%) patients with OSA (ICD 10: G47.3, ICD 9: 3472A). Baseline characteristics of the participants are presented in table 1 .

Population-based FINRISK surveys are independent random samples drawn from the population register of six geographic areas of Finland (North Karelia, Kuopio, Lapland, Oulu, Turku/Loimaa and Helsinki/Vantaa) and stratified according to gender, 10-year age group and study area. The survey included a mailed questionnaire and a clinical examination at which a blood sample was drawn. ${ }^{20}$ Participants from different survey years (1992, 1997, 2002 or 2007) were pooled together.

The total sample size for all FINRISK surveys was 29257 and participants who had missing information $(\mathrm{n}=7)$ or T1D $(n=297)$ were excluded from the study. Thus, the total sample size was 28953 where 13792 male and 15161 female participants aged 24-74 years at baseline were included in the analyses. Of these participants, 1214 $(4.2 \%)$ had OSA.

The H2000 Study is a comprehensive combination of health interview and health examination survey. The study was based on a nationally representative sample of 8028 persons aged $\geq 30$ years living in mainland Finland. ${ }^{21}$ After excluding participants who had missing information $(n=1331)$ or T1D $(n=92)$, the final dataset consisted of 6605 participants, 2940 men and 3707 women. Out of this cohort $235(3.6 \%)$ participants were diagnosed with OSA.

The Botnia Study was established in 1990 to investigate familial clustering of diabetes in the Ostrobothnia region in western Finland, and the non-diabetic participants have been prospectively followed. ${ }^{22}$ The population-based PPP-Botnia Study was conducted in the same geographical area. ${ }^{23}$ From the Botnia/PPP Botnia Studies (referred to as Botnia Study), we included 1405 patients with T2D, 735 men and 670 women. In this cohort, 119 participants $(8.5 \%)$ had OSA diagnosis.

\section{Patient and public involvement}

Patients and public were not involved in the designing process of this study. The patients will not be informed individually of the study results otherwise than through possible media coverage.

\section{Prospective follow-up and event definitions}

During the follow-up of the study cohorts, data for hospitalisations and causes of death were obtained from the Finnish National Hospital Discharge Register and the Finnish National Causes-of-Death Register. These registers have excellent validity and coverage ${ }^{24}{ }^{25}$ Follow-up for FINRISK ended on 31 December 2014, for H2000 on 31 December 2013 and for Botnia on 31 December 2015.

In the FINRISK cohorts, the follow-up was up to 22 years (median 12.9 years, IQR 8.5-17.9) and in the $\mathrm{H} 2000$ the follow-up was up to 14.5 years (median 13.9, IQR 13.6-14.2). In the Botnia, the follow-up was up to 25 years (median 14.7 years, IQR 10.2-21.4). Altogether we had 523372 person years of follow-up.

OSA diagnosis is based on ICD codes which usually are based on subjective symptoms, clinical examination and sleep registration applying Apnoea-Hypopnea Index (number of apnoeas and hypopnoeas per hour of sleep) $\geq 5 .{ }^{26}$ Incident CHD events were defined as the first occurrence of myocardial infarction, CHD death or coronary revascularisation procedure at any time between the baseline examination and final follow-up date. Incident stroke events (STR), and diabetic kidney disease (including codes from ICD 10: N18, N19, E102, E112, ICD 9: 585, 2503A, 2503B and ICD8: 58200, 25004) were defined as the first occurrence of such event during this time period in hospital discharges or causes of deaths register. In FINRISK and H2000 cohorts, incident T2D was registered as the first occurrence of T2D in hospital discharges, causes-of-deaths register or entitlement to a reimbursed diabetes medication. Also, diabetes medication purchases were checked. If diabetic medication was the only evidence, at least three separate purchases were required. Persons with gestational or T1D were excluded from the analyses. In the Botnia Study, diabetes was defined based on a $75 \mathrm{~g}$ oral glucose tolerance test, with plasma glucose $\geq 7.0 \mathrm{mmol} / \mathrm{L}$ at fasting plasma glucose (FPG) or $\geq 11.1 \mathrm{mmol} / \mathrm{L}$ at 2 hours or previous diagnosis and use of antidiabetic medication.

ICD codes for each endpoint definition can be found in online supplementary table 1 .

\section{Statistical methods}

We tested associations between OSA and incident CHD events, diabetic kidney disease events and T2D using Cox proportional hazard models. Age at onset of OSA was used as a time-dependent covariate in our analyses and age was used as the timescale. In such Cox model, a person contributes in the model only for his/her at-risk period (ie, for a certain age range). During that period, he/she could become an OSA case, before the T2D diagnosis or cardiovascular event. In this case, using OSA as 


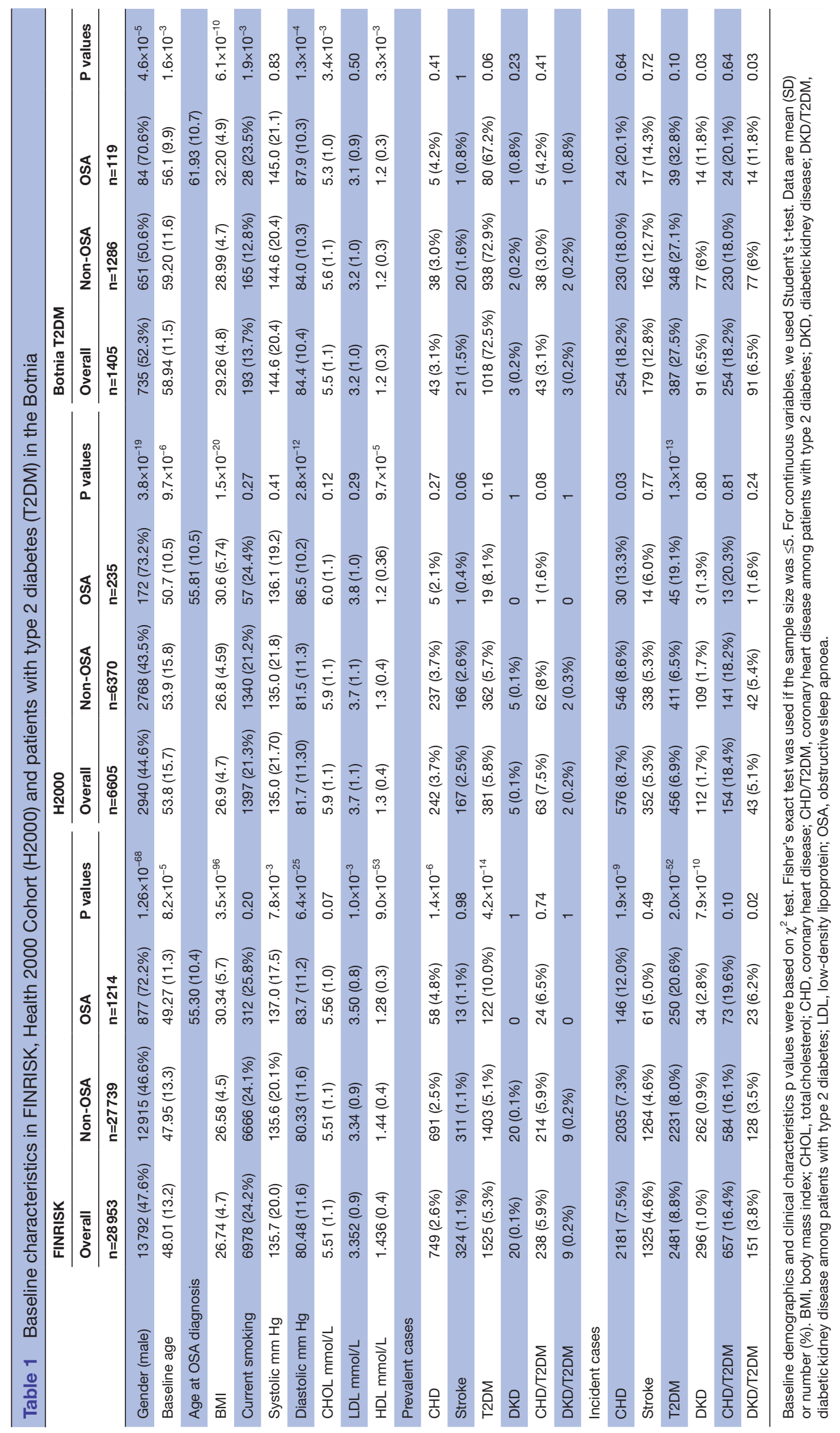


a time-dependent covariate, he/she contributes to the model as a non-OSA case until the age at OSA diagnosis, and as an OSA case for the remaining of his/her at-risk period. ${ }^{27}$ Prevalent cases were excluded from the Cox regression analyses and the assumptions of the models were tested by cox.zph-function.

In our FINRISK raw model for CHD, we used age, gender, geographical area and cohort year as covariates. In the adjusted model, we used, in addition to aforementioned factors, traditional risk factors as covariates for cardiovascular events: HDL, total cholesterol (CHOL), current cigarette smoking, BMI, hypertension (defined as a measured blood pressure of at least 140/90 $\mathrm{mm} \mathrm{Hg}$ or the use of antihypertensive medications), prevalent T2D and family history of stroke or myocardial infarction.

In the raw analysis, similar to CHD, the association between OSA and T2D was adjusted for age, gender, geographical area and cohort year. In the adjusted model, we used also BMI as a covariate. Among patients with T2D with the endpoint of diabetic kidney disease, the model was adjusted for BMI and hypertension.

In the H2000, we were not able to adjust the model for family history of stroke or myocardial infarction because that information was not determined in the study. Otherwise, the Cox time-dependent hazard model was adjusted for the same risk factors as mentioned before.

We combined the evidence from the FINRISK and H2000 to analyse CHD and T2D. To analyse T2D complications in more detail, we used the Botnia as a third cohort. The results were combined using fixed-effect meta-analysis.
Differences in baseline demographics and clinical characteristics were tested using $\chi^{2}$ tests. Fisher's exact test was used if the expected cell size was $\leq 5$. For continuous variables, we used Student's t-test (table 1). We considered $\mathrm{p}<0.05$ as statistically significant, and all tests were two sided.

The R statistical package (V.3.2.5) was used for all analyses (www.r-project.org). ${ }^{27}$

\section{RESULTS \\ General results}

To analyse the comorbidity of OSA and CHD, T2D outcomes and T2D complications, we combined longitudinal data from three population-based cohorts including 36963 participants with 1568 (4.2\%) patients with OSA. These cohorts included FINRISK $(n=28953)$ with follow-up of up to 22 years (median 12.9 years, IQR 8.5-17.9), H2000 ( $\mathrm{n}=6605)$ with the median follow-up of 13.9 (IQR 13.6-14.2) and patients with T2D from the Botnia Study ( $\mathrm{n}=1405)$ with the median follow-up of 15.3 years (IQR 10.8-21.34). Altogether we had 6248 patients with T2D (16.9\%).

We used the Finnish nationwide health registry data to construct diagnosis events. To evaluate the performance of the diagnostic events, we compared the main risk factor distributions between OSA cases and the rest of the population. In figure 1, we show that BMI and systolic blood pressure are on average higher and HDL lower in the OSA group compared with the rest of the population. Table 1 . presents a more thorough comparison of the groups.
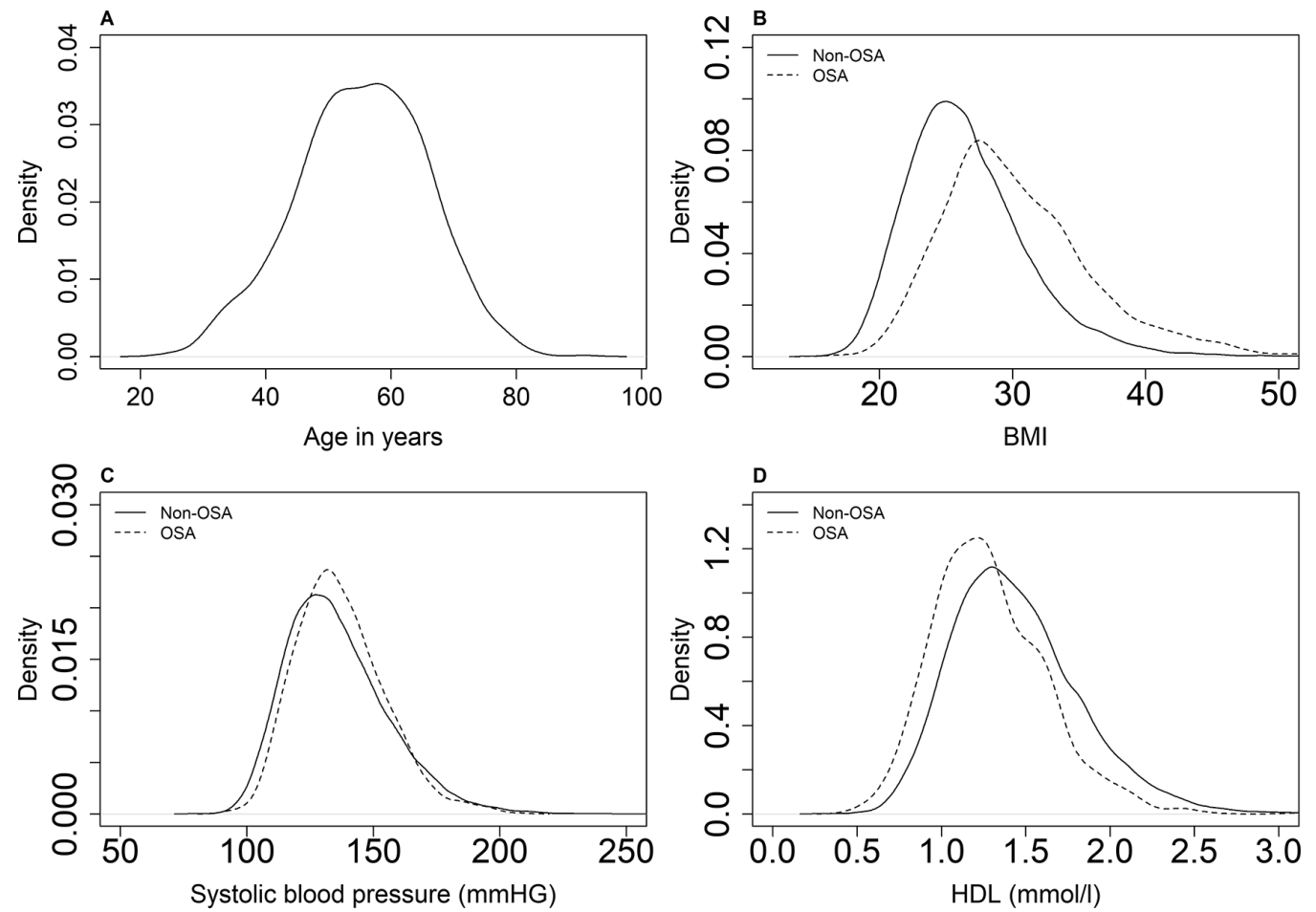

Figure 1 (A) Distributions of age at obstructive sleep apnoea (OSA) diagnosis (mean 55.31 years) and (B) significant differences in body mass index (BMI) $\left(p=3.49 \times 10^{-96}\right)$, (C) systolic blood pressure $\left(p=7.78 \times 10^{-3}\right)$ and $(D) H D L\left(p=8.98 \times 10^{-53}\right.$ among patients with OSA and non-OSA individuals in FINRISK. 
Table 2 HRs between individuals with obstructive sleep apnoea and the population for incident coronary heart disease events

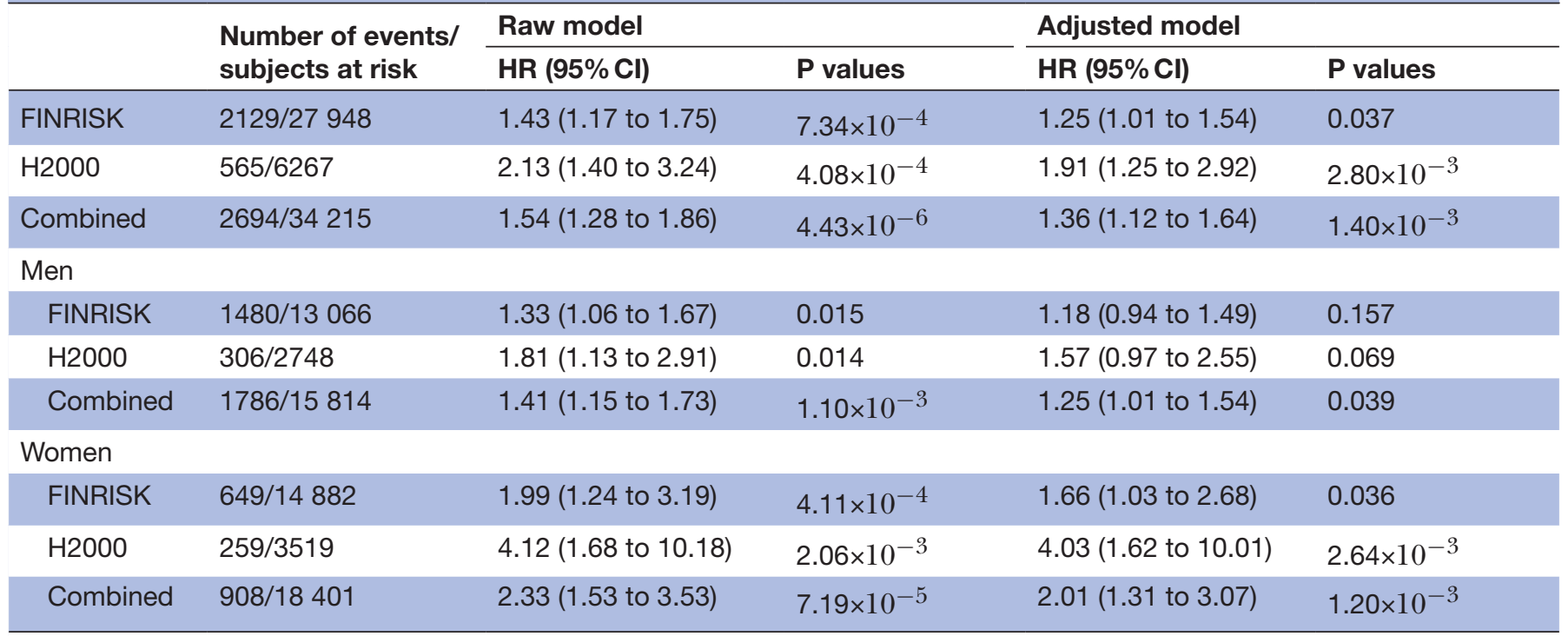

The FINRISK raw model is adjusted for age, cohort year, geographical area and gender. The adjusted model is adjusted for HDL and total cholesterol, current cigarette smoking, body mass index (BMI), hypertension, prevalent type 2 diabetes and family history of stroke or myocardial infarction in addition to covariates of the raw model. The Health 2000 Cohort $(\mathrm{H} 2000)$ raw model is adjusted for geographical area and gender. $\mathrm{H} 2000$-adjusted model is adjusted for $\mathrm{HDL}$ and total cholesterol, current cigarette smoking, BMI, hypertension and prevalent type 2 diabetes in addition to covariates of the raw model.

\section{Cardiovascular outcomes}

We first tested if OSA is associated with risk of incident CHD. In a model adjusted for age, sex and geographical region, OSA diagnosis elevates the risk of $\mathrm{CHD}(\mathrm{HR}=1.54$, $95 \%$ CI 1.28 to $1.86, \mathrm{p}=4.43 \times 10^{-6}$; table 2 , online supplementary figures 1,2 ).

When adjusting for CHD risk factors (age, sex, region, HDL and CHOL, current cigarette smoking, BMI, hypertension, T2D baseline and family history of stroke or myocardial infarction), the HR attenuated to 1.36 (95\% CI 1.12 to $1.64, \mathrm{p}=1.40 \times 10^{-3}$ ). The estimates were similar across these cohorts and were slightly higher for women (adjusted HR=2.01, 95\% CI 1.31 to $3.07, \mathrm{p}=1.20 \times 10^{-3}$ than for men (adjusted HR=1.25, 95\% CI 1.01 to 1.54 , $\mathrm{p}=0.039$ ). OSA did not, however, associate with stroke risk (online supplementary table 2).

\section{The effect of OSA on T2D and its complications}

We next tested if OSA modifies the risk for T2D. Among patients with OSA, this risk was elevated $(\mathrm{HR}=2.52$, $\mathrm{p}=1.91 \times 10^{-32}, 95 \%$ CI 2.16 to 2.93$)$. After further adjustment for BMI, the risk remained at 1.48 -fold $\left(\mathrm{p}=9.11 \times 10^{-7}\right.$, 95\% CI 1.26 to 1.73 ) showing a similar effect in both cohorts (online supplementary figures 2,3). Again, the effect was more prominent in women (adjusted HR $=1.63,95 \%$ CI 1.20 to $\left.2.23, \mathrm{p}=2.20 \times 10^{-3}\right)$ than in men $(\mathrm{HR}=1.44,95 \% \mathrm{CI}$ 1.27 to $2.21, \mathrm{p}=9.62 \times 10^{-5}$ ) (table 3$)$.

To analyse T2D complications more in detail, we included the Botnia cohort into the meta-analysis. H2000 lacked incident diabetic kidney disease events among patients with OSA.
Among patients with T2D, OSA elevated the risk for diabetic kidney disease ( $\mathrm{HR}=2.16,95 \%$ CI 1.40 to 3.34 , $\mathrm{p}=5.00 \times 10^{-4}$; table 4$)$.

When adjusted for the known risk factors for diabetic kidney disease (BMI and hypertension), the HR was slightly reduced to 1.75 (95\% CI 1.13 to $2.71, \mathrm{p}=0.013$, online supplementary figures 4,5$)$. The effects were similar in both cohorts.

Among patients with T2D, OSA alone increased the risk for CHD by 1.40 (95\% CI 1.10 to $1.81, \mathrm{p}=8.50 \times 10^{-3}$ ; table 4). This was almost unaffected by adding the following risk factors: HDL and CHOL, current cigarette smoking, BMI, hypertension and family history of stroke or myocardial infarction (HR=1.36, 95\% CI 1.05 to 1.76 , $\mathrm{p}=0.019$, online supplementary figures 4,5 ).

\section{The effect of OSA to mortality risk}

We also examined whether OSA was an independent risk factor for all-cause mortality. OSA increased the risk in the raw model $(\mathrm{HR}=1.18,95 \%$ CI 1.00 to $1.40, \mathrm{p}=0.057)$ and this risk attenuated after adjustment for other risk factors. Among T2D individuals, OSA increased the all-cause mortality risk in the raw model ( $\mathrm{HR}=1.40,95 \%$ CI 1.21 to $\left.1.62, \mathrm{p}=2.03 \times 10^{-6}\right)$ and after adjustments $(\mathrm{HR}=1.35,95 \% \mathrm{CI}$ 1.06 to $1.71, \mathrm{p}=0.016$; table 5 , online supplementary figure $6)$.

\section{DISCUSSION}

Our results from three prospective population-based cohorts found a severe impact of OSA on cardiovascular health, T2D and mortality during a life course. We demonstrate that OSA is an independent risk factor for CHD and 
Table 3 HRs between individuals with obstructive sleep apnoea and the population for incident type 2 diabetes

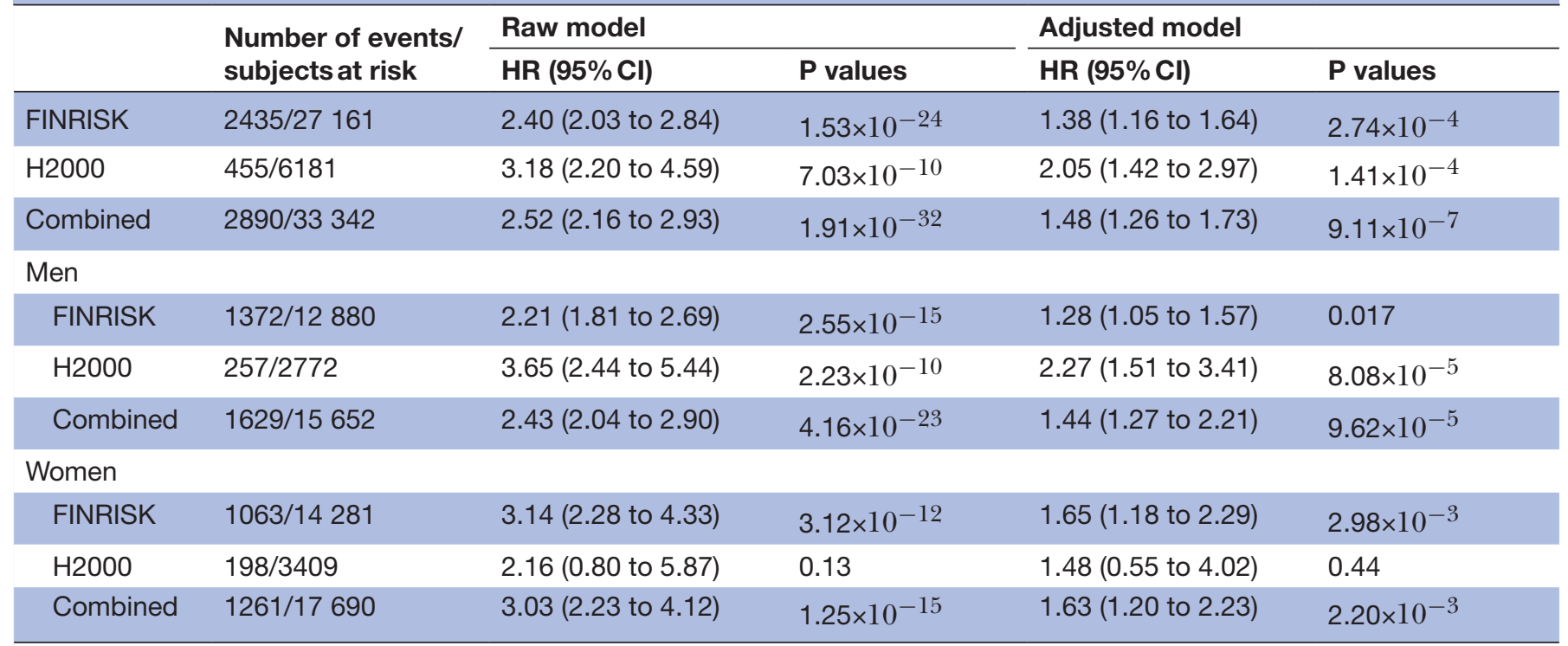

The FINRISK raw model is adjusted for age, cohort year, geographical area and gender. The adjusted model is adjusted for body mass index (BMI) in addition to covariates of the raw model. The Health 2000 Cohort (H2000) raw model is adjusted for geographical area and gender.

The adjusted model is adjusted for BMI in addition to covariates of the raw model.

T2D in the general population. Using a combination of population cohorts and a T2D cohort, Botnia, we present evidence for the role of OSA in the risk of T2D complications. To our knowledge, this is the largest study of the role of OSA in CHD and T2D diseases, combining sample size of over 36000 individuals with up to $20+$ years of follow-up.

These results allow us to draw several conclusions. First, our results illustrate that nationwide health registry data can successfully be used to identify cases of OSA. Second, the registry-based OSA cases revealed an increased risk for future CHD events and T2D. This risk was surprisingly high in women, even after adjusting for risk factors, shedding new light to the potential sex differences in OSA. This finding may provide tools to identify particularly women in high risk of CHD and T2D. Third, we observed convincing evidence indicating that T2D accumulated to patients with OSA independent of obesity.

OSA seems to increase the risk for CHD to the same extent in diabetic and non-diabetic individuals but the risk of diabetic kidney disease was $75 \%$ higher among patients with OSA compared with diabetic individuals without OSA diagnosis. All-cause mortality was increased by OSA among

Table 4 HRs for type 2 diabetes complications

\begin{tabular}{|c|c|c|c|c|c|}
\hline & \multirow{2}{*}{$\begin{array}{l}\text { Number of events/ } \\
\text { subjects at risk }\end{array}$} & \multicolumn{2}{|l|}{ Raw model } & \multicolumn{2}{|l|}{ Adjusted model } \\
\hline & & HR $(95 \%$ Cl) & $P$ values & HR $(95 \% \mathrm{Cl})$ & P values \\
\hline \multicolumn{6}{|l|}{ DKD } \\
\hline FINRISK & $147 / 3932$ & 2.15 (1.27 to 3.62$)$ & $4.10 \times 10^{-3}$ & 1.72 (1.01 to 2.93 ) & 0.044 \\
\hline Botnia & $91 / 1380$ & 2.19 (1.003 to 4.79$)$ & 0.049 & 1.80 (0.82 to 3.96$)$ & 0.143 \\
\hline Combined & $238 / 5312$ & 2.16 (1.40 to 3.34$)$ & $5.00 \times 10^{-4}$ & 1.75 (1.13 to 2.71$)$ & 0.013 \\
\hline \multicolumn{6}{|l|}{$\mathrm{CHD}$} \\
\hline FINRISK & $640 / 3710$ & 1.44 (1.07 to 1.95$)$ & 0.016 & 1.40 (1.04 to 1.90$)$ & 0.028 \\
\hline $\mathrm{H} 2000$ & $152 / 761$ & 1.46 (0.74 to 2.82$)$ & 0.272 & 1.46 (0.74 to 2.89$)$ & 0.274 \\
\hline Botnia & $236 / 1253$ & $1.18(0.60$ to 2.31$)$ & 0.630 & 1.07 (0.54 to 2.11$)$ & 0.840 \\
\hline Combined & $1028 / 5724$ & $1.40(1.10$ to 1.81$)$ & $8.50 \times 10^{-3}$ & 1.36 (1.05 to 1.76$)$ & 0.019 \\
\hline
\end{tabular}

The FINRISK raw models are adjusted for age, cohort year, geographical area and gender. The Health 2000 Cohort (H2000) raw models are adjusted for age, geographical area and gender. The Botnia raw models are adjusted for age and gender. The adjusted models for diabetic kidney disease (DKD) are adjusted for body mass index (BMI) and hypertension in all cohorts in addition to covariates of the raw model. The FINRISK-adjusted model for coronary heart disease (CHD) is adjusted for HDL and total cholesterol, current cigarette smoking, $\mathrm{BMI}$, hypertension and family history of stroke or myocardial infarction in addition to covariates of the raw model. The H2000-adjusted and Botnia-adjusted models for $\mathrm{CHD}$ are adjusted for $\mathrm{HDL}$ and total cholesterol, current cigarette smoking, BMI and hypertension in addition to covariates of the raw model. 
Table 5 HRs for all-cause mortality among general population and individuals with type 2 diabetes (T2DM)

\begin{tabular}{|c|c|c|c|c|c|}
\hline & \multirow{2}{*}{$\begin{array}{l}\text { Number of events/ } \\
\text { subjects at risk }\end{array}$} & \multicolumn{2}{|l|}{ Raw model } & \multicolumn{2}{|l|}{ Adjusted model } \\
\hline & & HR (95\% Cl) & P values & HR (95\% Cl) & $P$ values \\
\hline \multicolumn{6}{|c|}{ General population } \\
\hline H2000 & $1286 / 6498$ & 1.65 (1.14 to 2.39$)$ & $7.91 \times 10^{-3}$ & 1.74 (1.20 to 2.52 ) & $3.68 \times 10^{-3}$ \\
\hline Combined & $4514 / 35164$ & 1.18 (1.00 to 1.40$)$ & 0.057 & $1.13(0.95$ to 1.34$)$ & 0.161 \\
\hline FINRISK & $719 / 3940$ & 1.37 (1.01 to 1.84$)$ & 0.041 & $1.23(0.91$ to 1.67$)$ & 0.179 \\
\hline H2OOO & $284 / 820$ & 1.35 (0.68 to 2.71$)$ & 0.390 & 1.48 (0.74 to 2.98$)$ & 0.267 \\
\hline Botnia & $348 / 1309$ & $1.84(1.14$ to 2.99$)$ & $1.44 \times 10^{-4}$ & 1.62 (1.00 to 2.65$)$ & 0.052 \\
\hline Combined & $1351 / 6069$ & 1.40 (1.21 to 1.62$)$ & $2.03 \times 10^{-6}$ & 1.35 (1.06 to 1.71$)$ & 0.016 \\
\hline
\end{tabular}

The FINRISK raw models are adjusted for age, cohort year, geographical area and gender. The Health 2000 Cohort (H2000) raw models are adjusted for age, geographical area and gender. The Botnia raw models are adjusted for age and gender. The FINRISK-adjusted model is adjusted for HDL and total cholesterol, current cigarette smoking, body mass index (BMI), hypertension and family history of stroke or myocardial infarction in addition to covariates of the raw model. The H2000-adjusted and Botnia-adjusted models are adjusted for HDL and total cholesterol, current cigarette smoking, BMI and hypertension in addition to covariates of the raw model. Adjusted models for general population are also adjusted for prevalent T2DM.

patients with T2D but not significantly in the general population. The main cause of mortality was CHD both in diabetics $(33.8 \%)$ and in the general population $(30.8 \%)$.

While previous studies mostly lacked the longitudinal dimension, also our study has limitations: (1) registry-based ascertainment through hospitalisation may miss non-hospitalised cases (false negatives) and (2) treatment information such as Continuous Positive Airway Pressure (CPAP) compliance and (3) OSA severity, emphasising more severe OSA cases affecting the hazard estimates. However, in spite of these limitations, the study design provides comprehensive estimates of the adverse effects of OSA on CHD and T2D disorders. This is supported by a recent meta-analysis reporting an risk ratio (RR) of 1.49 for the association of OSA and T2D ${ }^{28}$ which is well in line with the results from our study.

It is being increasingly recognised that OSA can accelerate loss of kidney function, ${ }^{29}$ but OSA usually presents with other risk factors of kidney function like obesity, T2D and hypertension. ${ }^{30}{ }^{31}$ It has been hypothesised that there is a bidirectional relationship between OSA and kidney disease, where kidney disease promotes OSA and OSA kidney disease. ${ }^{29}$ Our study supports the latter hypothesis that in patients with diabetes OSA increased the risk for kidney disease by 1.75fold after the adjustment for other risk factors. This is in line with previous, smaller studies. ${ }^{199}$

An important advantage of our large sample size was that we could investigate gender differences in the CHD and T2D risk associated with OSA. While we did not observe a significantly higher risk in women than in men, our data opposite to previous studies clearly show that the severe outcome of OSA is as severe in women as in men (if not more severe). ${ }^{332}$ It is possible explanation for this finding may be delayed diagnosis of OSA in women compared with men.

Taken together, our longitudinal study with up to 523372 person years of follow-up demonstrates that OSA is an independent risk factor for CHD and T2D and markedly increase risk for diabetic kidney disease. This emphasises the need to search for signs of OSA in patients with T2D with rapid progression of T2D and evaluate whether this progression can be halted by CPAP therapy.

\section{Author affiliations}

${ }^{1}$ Department of Oral and Maxillofacial Diseases, Helsinki University Hospital, Helsinki, Finland

${ }^{2}$ Orthodontics, Department of Oral and Maxillofacial Diseases, Clinicum, Faculty of Medicine, University of Helsinki, Helsinki, Finland

${ }^{3}$ Institute for Molecular Medicine Finland (FIMM/HiLIFE), University of Helsinki, Helsinki, Finland

${ }^{4}$ National Institute for Health and Welfare, Helsinki, Finland

${ }^{5}$ Endocrinology, Abdominal Centre, University of Helsinki and Helsinki University Hospital, Helsinki, Finland

${ }^{6}$ Diabetes and Obesity Research Program, University of Helsinki and Folkhälsan Research Center, Helsinki, Finland

${ }^{7}$ Sleep Unit, Heart and Lung Center, Helsinki University Hospital, Helsinki, Finland ${ }^{8}$ Department of Clinical Sciences, Lund University Diabetes Centre, Malmö, Sweden ${ }^{9}$ Department of Otorhinolaryngology-Head and Neck Surgery, University of Helsinki and Helsinki University Hospital, Helsinki, Finland

${ }^{10}$ Analytic and Translational Genetics Unit, Department of Medicine, Massachusetts General Hospital, Boston, Massachusetts, USA

${ }^{11}$ Department of Neurology, Massachusetts General Hospital, Boston,

Massachusetts, USA

${ }^{12}$ Department of Psychiatry, Massachusetts General Hospital, Boston,

Massachusetts, USA

${ }^{13}$ The Medical and Population Genomics Program, Broad Institute of MIT and Harvard, Cambridge, Massachusetts, USA

${ }^{14}$ Department of Public Health, University of Helsinki, Helsinki, Finland

Acknowledgements The authors would like to thank Sari Kivikko, Mervi Kinnunen and Elina Kilpeläinen for management assistance. The FINRISK data used for the research were obtained from THL Biobank and the Health 2000 data from THL. The skillful assistance of the Botnia Study Group is gratefully acknowledged. The authors thank all study participants and their advisers for their generous participation in the FINRISK, the Health 2000 and the Botnia studies.

Contributors TP, AP and SR conceived the study and designed the study protocol. SS conducted the literature review, statistical analysis and drafted the manuscript. AH contributed statistical analysis and phenotyped study samples. VS acquired the 
FINRISK data, TT and LG acquired the Botnia data and SK acquired the Health 2000 data. SS, TP, SR, AP, AH, LG, TT, AM, VS, SK and AB reviewed the manuscript for intellectual content, made revisions as needed and approved the final version for publication. TP, SR and AP supervised the study.

Funding This work was supported by Finnish Woman Dentists' Association, the Finnish Dental Society Apollonia, the Helsinki University Central Hospital Research Funds (HUS 369/2017), Academy of Finland Center of Excellence in Complex Disease Genetics (312062), Academy of Finland (251217 and 285380), The Finnish Foundation for Cardiovascular Research, the Sigrid Juselius Foundation and HiLIFE Fellows grants 2017-2020. The sources of funding had no role in study design, data collection, analyses, interpretation and decision to submit the article for publication. FINRISK surveys have been funded mainly by budgetary funds of the National Institute for Health and Welfare. Additional funding has been obtained as research grants from the Finnish Academy and several domestic foundations. VS was supported by the Finnish Foundation for Cardiovascular Research. The Health 2000 Study is funded by the National Institute for Health and Welfare (THL), the Finnish Centre for Pensions (ETK), The Social Insurance Institution of Finland (KELA), The Local Government Pensions Institution (KEVA) and other organizations listed on the website of the survey (http://www.terveys2000.fi). The Botnia and The PPP-Botnia studies (LG and TT) have been financially supported by grants from Folkhälsan Research Foundation, the Sigrid Juselius Foundation, The Academy of Finland (grants no. 263401, 267882, 312063 to LG, 312072 to TT), Nordic Center of Excellence in Disease Genetics, EU (EXGENESIS, EUFP7-MOSAIC FP7-600914), Ollqvist Foundation, Swedish Cultural Foundation in Finland, Finnish Diabetes Research Foundation, Foundation for Life and Health in Finland, Signe and Ane Gyllenberg Foundation, Finnish Medical Society, Paavo Nurmi Foundation, Helsinki University Central Hospital Research Foundation, Perklén Foundation, Närpes Health Care Foundation and Ahokas Foundation. The study has also been supported by the Ministry of Education in Finland, Municipal Health Care Center and Hospital in Jakobstad and Health Care Centers in Vasa, Närpes and Korsholm.

Competing interests None declared.

Patient consent Not required.

Ethics approval FINRISK data are stored in the THL Biobank which distributes them to researchers on the basis of written applications. The Coordinating Ethical Committee of the Helsinki and Uusimaa Hospital District has approved the THL Biobank with the decision \# 238/13/03/00/2014. H2000 Study protocol is approved by the Ethical Committee of the National Public Health Institute (decision number 8/99). The Botnia/PPP Botnia Study protocols were approved by the Ethics Committee of the Helsinki University Central Hospital, Finland, with the decision \#574/E5/03.

Provenance and peer review Not commissioned; externally peer reviewed.

Data sharing statement Data have been acquired from THL Biobank and are obtainable through the National Institute of Welfare, Finland. Additional information https://thl.fi/en/web/thl-biobank.

Open access This is an open access article distributed in accordance with the Creative Commons Attribution Non Commercial (CC BY-NC 4.0) license, which permits others to distribute, remix, adapt, build upon this work non-commercially, and license their derivative works on different terms, provided the original work is properly cited, appropriate credit is given, any changes made indicated, and the use is non-commercial. See: http://creativecommons.org/licenses/by-nc/4.0/.

\section{REFERENCES}

1. Kapur V, Strohl KP, Redline S, et al. Underdiagnosis of sleep apnea syndrome in U.S. communities. Sleep Breath 2002;6:049-54.

2. Wang X, Bi Y, Zhang Q, et al. Obstructive sleep apnoea and the risk of type 2 diabetes: a meta-analysis of prospective cohort studies. Respirology 2013;18:140-6.

3. Gottlieb DJ, Yenokyan G, Newman AB, et al. Prospective study of obstructive sleep apnea and incident coronary heart disease and heart failure: the sleep heart health study. Circulation 2010;122:352-60.

4. Kales A, Bixler EO, Cadieux RJ, et al. Sleep apnoea in a hypertensive population. Lancet 1984;2:1005-8.

5. Lavie P, Ben-Yosef R, Rubin AE. Prevalence of sleep apnea syndrome among patients with essential hypertension. Am Heart J 1984;108:373-6.

6. Kent BD, Grote L, Ryan S, et al. Diabetes mellitus prevalence and control in sleep-disordered breathing: the European Sleep Apnea Cohort (ESADA) study. Chest 2014;146:982-90.
7. Varvarigou V, Dahabreh IJ, Malhotra A, et al. A review of genetic association studies of obstructive sleep apnea: field synopsis and meta-analysis. Sleep 2011;34:1461-8.

8. Young T, Finn L, Peppard PE, et al. Sleep disordered breathing and mortality: eighteen-year follow-up of the Wisconsin sleep cohort. Sleep 2008;31:1071-8.

9. Peker Y, Hedner J, Norum J, et al. Increased incidence of cardiovascular disease in middle-aged men with obstructive sleep apnea: a 7-year follow-up. Am J Respir Crit Care Med 2002;166:159-65.

10. MARIN J, CARRIZO S, Vicente E, et al. Long-term cardiovascular outcomes in men with obstructive sleep apnoea-hypopnoea with or without treatment with continuous positive airway pressure: an observational study. The Lancet 2005;365:1046-53.

11. Beck MK, Westergaard D, Jensen AB, et al. Temporal order of disease pairs affects subsequent disease trajectories: the case of diabetes and sleep apnea. Pac Symp Biocomput 2017;22:380-9.

12. Botros N, Concato J, Mohsenin V, et al. Obstructive sleep apnea as a risk factor for type 2 diabetes. Am J Med 2009;122:1122-7.

13. Ronksley PE, Hemmelgarn BR, Heitman SJ, et al. Obstructive sleep apnoea is associated with diabetes in sleepy subjects. Thorax 2009;64:834-9.

14. Kendzerska T, Gershon AS, Hawker G, et al. Obstructive sleep apnea and incident diabetes. A historical cohort study. Am J Respir Crit Care Med 2014;190:218-25.

15. Reichmuth KJ, Austin D, Skatrud JB, et al. Association of sleep apnea and type II diabetes: a population-based study. Am J Respir Crit Care Med 2005;172:1590-5.

16. Ozol D, Carlıoğlu A, Karamanlı H, et al. Influence of snoring on microalbuminuria in diabetic patients. Sleep Breath 2011;15:295-300.

17. Leong WB, Nolen M, Thomas GN, et al. The impact of hypoxemia on nephropathy in extremely obese patients with type 2 diabetes mellitus. J Clin Sleep Med 2014;10:773-8.

18. Hwu DW, Lin KD, Lin KC, et al. The association of obstructive sleep apnea and renal outcomes-a systematic review and meta-analysis. BMC Nephrol 2017;18:313-731.

19. Tahrani AA, Ali A, Raymond NT, et al. Obstructive sleep apnea and diabetic nephropathy: a cohort study. Diabetes Care 2013;36:3718-25.

20. Borodulin K, Vartiainen E, Peltonen M, et al. Forty-year trends in cardiovascular risk factors in Finland. Eur J Public Health 2015;25:539-46.

21. Kattainen A, Salomaa V, Härkänen T, et al. Coronary heart disease: from a disease of middle-aged men in the late 1970s to a disease of elderly women in the 2000s. Eur Heart J 2006;27:296-301.

22. Groop L, Forsblom C, Lehtovirta M, et al. Metabolic consequences of a family history of NIDDM (the Botnia study): evidence for sexspecific parental effects. Diabetes 1996;45:1585-93.

23. Isomaa $\mathrm{B}$, Forsén $\mathrm{B}$, Lahti $\mathrm{K}$, et al. A family history of diabetes is associated with reduced physical fitness in the Prevalence, Prediction and Prevention of Diabetes (PPP)-Botnia study. Diabetologia 2010;53:1709-13.

24. Tolonen H, Salomaa V, Torppa J, et al. The validation of the finnish hospital discharge register and causes of death register data on stroke diagnoses. Eur J Cardiovasc Prev Rehabil 2007;14:380-5.

25. Pajunen $P$, Koukkunen $H$, Ketonen $M$, et al. The validity of the Finnish Hospital Discharge Register and Causes of Death Register data on coronary heart disease. Eur J Cardiovasc Prev Rehabil 2005;12:132-7.

26. Laitinen LA, Anttalainen U, Pietinalho A, et al. Sleep apnoea: Finnish National guidelines for prevention and treatment 2002-2012. Respir Med 2003;97:337-65.

27. Anonymous. https://cran.r-project.org/web/packages/survival/ vignettes/timedep.pdf

28. Anothaisintawee T, Reutrakul S, Van Cauter E, et al. Sleep disturbances compared to traditional risk factors for diabetes development: Systematic review and meta-analysis. Sleep Med Rev 2016;30:11-24.

29. Abuyassin B, Sharma K, Ayas NT, et al. Obstructive sleep apnea and kidney disease: a potential bidirectional relationship? J Clin Sleep Med 2015;11:915-24.

30. Tada T, Kusano KF, Ogawa A, et al. The predictors of central and obstructive sleep apnoea in haemodialysis patients. Nephrol Dial Transplant 2007;22:1190-7.

31. Wolf J, Lewicka J, Narkiewicz K. Obstructive sleep apnea: an update on mechanisms and cardiovascular consequences. Nutr Metab Cardiovasc Dis 2007;17:233-40.

32. Punjabi NM, Caffo BS, Goodwin JL, et al. Sleep-disordered breathing and mortality: a prospective cohort study. PLoS Med 2009;6:e1000132. 